\title{
Spectrophotometric Determination of the Ionization Constant of 2,4,6-Trinitro-m-cresol in Water at $25{ }^{\circ} \mathrm{C}$
}

\author{
Marion Maclean Davis and Maya Paabo
}

\author{
(August 10, 1960) \\ The ionization constant of 2,4,6-trinitro- $m$-cresol in water at $25^{\circ} \mathrm{C}$ was determined by a \\ spectrophotometric procedure. The $p \mathrm{~K}$ value $0.81(\mathrm{~K} \approx 0.16)$ was obtained.
}

\section{Introduction}

J. Kendall [1] ${ }^{1}$ determined the conductivity of $2,4,6$-trinitro- $m$-cresol (methylpicric acid) and its sodium salt in water, and concluded that a saturated solution $(0.01-M)$ at $25^{\circ} \mathrm{C}$ is about 92 -percent dissociated. Applying the method of calculation described in [2] to these data gives a $p \mathrm{~K}$ value of about 1 tor trinitro- $m$-cresol. Values of $p \mathrm{~K}$ for trinitro- $m$ cresol can be estimated by assuming that effects of substituents on the ionization constants of phenols are additive [2]. For example, by applying data for pbenol and its monosubstituted derivatives the estimated $p \mathrm{~K}$ value 1.66 is obtained. Data for 2,4-dinitropbenol, o-nitrophenol, and m-cresol lead to the $p \mathrm{~K}$ value 1.41 . A lower $p \mathrm{~K}$ value, 0.95 , is obtained by using $p \mathrm{~K}$ values for 2,6-dinitrophenol, $p$-nitrophenol, and $m$-cresol. However, a substantially higher $p \mathrm{~K}$ value (2.8) was obtained by a potentiomstric procedure [3].

This paper describes the determination of $p \mathrm{~K}$ for trinitro-m-cresol by a spectrophotometric procedure.

\section{Method and Results}

Commercial 2,4,6-trinitro-m-cresol of high purity was recrystallized successively from water, aqueous ethanol, and benzene-cyclohexane, and then dried at $80{ }^{\circ} \mathrm{C}$ for $2 \mathrm{hr} ; \mathrm{mp}, 107.0$ to $107.5^{\circ} \mathrm{C}$. Potentiometric weight-titrations indicated the purity was greater than 99.8 percent.

The spectrophotometric procedure used for determining $p \mathrm{~K}$ was closely analogous to that described in [2]. In figure 1 molar absorption curves for ionized and nonionized trinitro- $m$-cresol are shown. Additional absorption curves were obtained in which the hydrochloric acid content varied from about $0.05-M$ to $6-M$. The two isosbestic points shown in figure 1 remained fixed throughout.

Values of $p \mathrm{~K}$ were calculated from absorbance measurements at $350 \mathrm{~m}_{\mu}, 380 \mathrm{~m}_{\mu}$, and $410 \mathrm{~m}_{\mu}$.

\footnotetext{
1 Figures in brackets indicate the literature references at the end of this paper.
}

The data and the calculated values of $p \mathrm{~K}$ are summarized in table 1 . These yield the average $p K$ value 0.806 , or approximately 0.81 . The corresponding ionization constant is 0.156 .

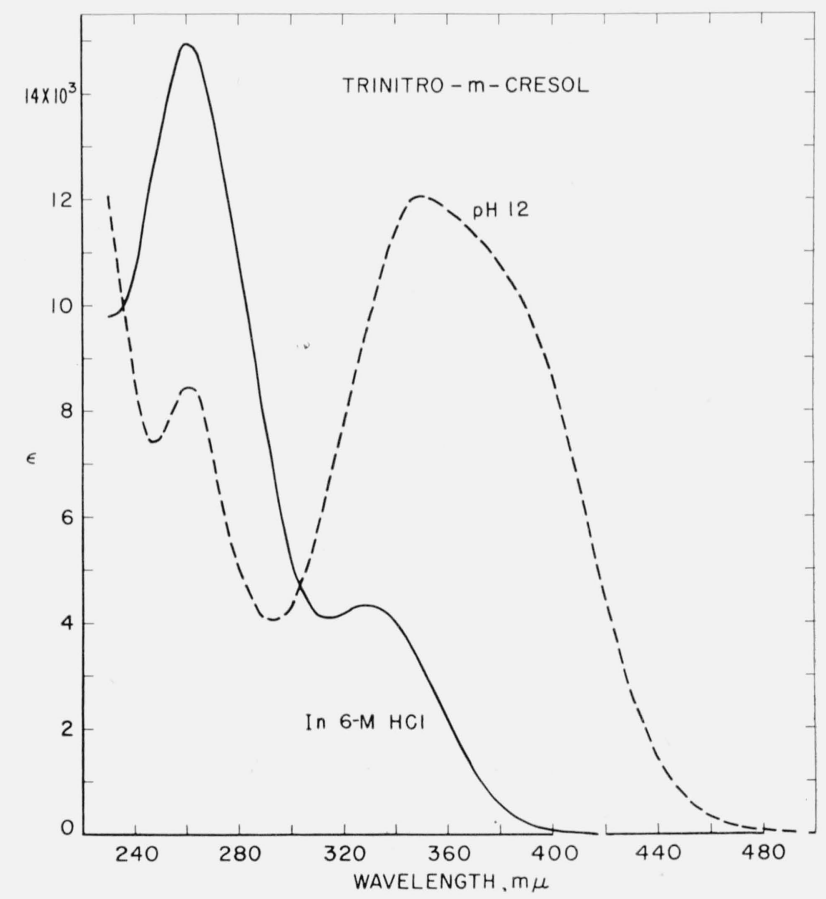

FIgure 1. Spectral absorption curves of 2,4,6-trinitro-mcresol in aqueous acid (approx. 6- $\mathrm{M} \mathrm{HCl)}$ and in aqueous alkali $(\mathrm{NaOH}, p \mathrm{H} \approx 12)$.

The curve for a solution containing 4.5-M HCl was almost identical with that shown for $6-M$ hydrochloric acid solution.

\section{References}

[1] J. Kendall, Proc. Roy. Soc. (London) A85, 200 (1911).

[2] M. M. Davis, M. Paabo, and R. A. Robinson, J. Research NBS 64A, 531 (1960).

[3] C. E. Moore and R. Peck, J. Org. Chem. 20, 673 (1955). 
TABLE 1. Ionization constant of 2,4,6-trinitro-m-cresol in water at $25^{\circ} \mathrm{C}$ a,b

\begin{tabular}{c|r|r|r|r|r}
\hline \hline & & & \\
Concentra- \\
tion of HCl
\end{tabular}

${ }^{a}$ The concentration of trinitro- $m$-cresol was $5.001 \times 10^{-5} M$. The optical absorption cells were $1 \mathrm{~cm}$ in length.

${ }^{b}$ All concentrations are in moles per liter.

c $p \mathrm{~K}=-\log \left[\mathrm{H}^{+}\right]-2 \log \gamma \pm-\log \left[\left(D-D_{1}\right) /\left(D_{2}-D\right)\right]$. See [2].

d Discarded.

(Paper 64A6-78) 